\title{
Antibiotic prophylaxis for transrectal ultrasound-guided prostatic biopsies: a comparison of two regimens
}

\author{
Mostafa Faty, Saleh M. Saleh, Ahmed R. El-Nahas ${ }^{*}$ (D, Tariq F. Al-Shaiji and Abdullatif Al-Terki
}

\begin{abstract}
Background: There were controversies about the appropriate antibiotic prophylaxis regimen in order to decrease the incidence of post-transrectal ultrasound-guided prostatic biopsies (TRUS-PB) infectious complications. This study was conducted to compare the efficacy of two antibiotics prophylaxis regimens for TRUS-PB. In group 1, patients received single IV dose of $1 \mathrm{~g}$ amikacin $30 \mathrm{~min}$ before the procedure followed by oral ciprofloxacin $500 \mathrm{mg}$ immediately after TRUS-PB. Group 2 patients received the same antibiotics, but ciprofloxacin started 1 day prior to TRUS-PB. Then ciprofloxacin was given twice daily for a total of 5 days in both groups.

Results: The study included 146 patients (54 in group 1 and 92 in group 2). The baseline characters (age, comorbidities, ASA score, PSA, prostate size and presence of urethral catheter) were comparable for both groups. Post-biopsy sepsis was observed in three patients (5.6\%) in group 1 and one patient in group $2(1.1 \%, P=0.143)$. Sepsis was successfully managed in three, while one patient (1.9\%) from group 1 required ICU admission for management of septic shock.
\end{abstract}

Conclusions: The incidence of sepsis after TRUS-PB is low when dual antibiotic prophylaxis (ciprofloxacin and amikacin) was used. Starting ciprofloxacin 1 day before TRUS-PB decreased the incidence of sepsis as well as its severity.

Keywords: Prostate, Biopsy, Transrectal ultrasound, Sepsis, Antibiotic prophylaxis

\section{Background}

Prostate cancer is the second most commonly diagnosed cancer in men after cutaneous cancers [1]. Prostatic needle biopsy is currently the standard technique to obtain tissue for histological diagnosis of prostate cancer. Recent studies have showed that approximately one million prostatic biopsies are performed per year in the USA [2]. TRUS-guided prostate biopsies (TRUS-PB) technique is considered to be a relatively low-risk outpatient procedure with some minor self-limiting complications such as rectal bleeding and hematospermia [3]. However, major complications necessitating emergency department visits and hospital admissions such as sepsis, urinary retention

*Correspondence: arelnahas69@gmail.com

Urology Unit, Surgery Department, Al-Amiri Hospital, Gulf Road, Sharq, 20002 Kuwait City, Kuwait and gross hematuria were also reported in a minority of patients [4].

Post-TRUS-PB hospital admissions have escalated at alarming rates during the last 10 years secondary to the rising rate of infection-related complications [5]. The European Association of Urology (EAU) guidelines for antibacterial prophylaxis for TRUS-PB recommend fluoroquinolones as a first choice due to their broad spectrum of activity, excellent penetration into prostatic tissue, and their prolonged post-antibiotic effect [6]. As a consequence of being the current prophylaxis of choice for most urologic procedures, the wide spread of fluoroquinolone has led to colonization of rectal flora with fluoroquinolone resistant $E$. coli in $23 \%$ of patients undergoing prostate biopsy [7]. This resulted in increase in the number of post-TRUS-PB infections and sepsis in the last 
few years, and most cases of sepsis in the recent literature are triggered by fluoroquinolone-resistant E. coli [7].

There were controversies about the appropriate antibiotic prophylaxis regimen in order to decrease the incidence of infectious complications. Joel et al. surveyed 3355 urologists in USA and reported 14 different durations of treatment using 10 different classes of antibiotic [8]. Timing for start of the antibiotic was also different as some proved giving the antibiotic immediately after prostate biopsy was as effective as giving it $30 \mathrm{~min}$ [9] or $2 \mathrm{~h}$ before the biopsies [10]. On the other hand, it was proved that giving the antibiotic $24 \mathrm{~h}$ before prostatic biopsies reduced relative risk of infection by $55 \%$ compared with antibiotics given just prior to the procedure [11].

We conducted this study to compare the efficacy of two antibiotics prophylaxis regimens for TRUS-PB.

\section{Methods}

The archived files for patients who underwent TRUS-PB between January 2012 and August 2018 were retrospectively reviewed after IRB approval of the study protocol. Pre-biopsy evaluation included history, digital rectal examination (DRE), PSA, INR and urine culture. Inclusions criteria were abnormalities in DRE and/or high PSA in relation to patients' age. Patients with coagulopathies or receiving corticosteroids or immune suppression were not included. Those with active UTI (positive urine culture) received the specific antibiotic, and the procedure was postponed until urine culture became sterile. Patients receiving antiplatelets stopped them (after consultation of the treating doctor) for sufficient time before the biopsies.

\subsection{Antibiotic prophylaxis protocols}

Patients who underwent TRUS-PB between January 2012 and April 2015 represent group 1. They received single IV dose of $1 \mathrm{~g}$ Amikacin $30 \mathrm{~min}$ prior to the procedure then oral ciprofloxacin $500 \mathrm{mg}$ immediately after TRUS-PB for 5 days. Group 2 included patients who underwent TRUSPB between May 2015 and August 2018. In addition to the single IV dose of $1 \mathrm{~g}$ amikacin, they received oral ciprofloxacin $500 \mathrm{mg} 1$ day before the biopsy and continued twice daily for a total of 5 days.

\subsection{Technique of TRUS-PB}

All patients received bowel preparation one night before the procedure (Picolax ${ }^{\circledR}$, Ferring pharmaceutical, UK). The same biopsy technique was performed by two urologists (MF and SMS) who are experienced in TRUS-PB for all patients. In a left lateral position after applying local anesthetic (Xylocain gel), a Voluson ${ }^{\circledR}$ E6 machine (GE medical system, Milwaukee, USA) was used, with a side-firing probe; Voluson ${ }^{\circledR}$ Endocavity transducer. The prostate was scanned from its apex to base, and the prostatic volume was calculated. A systematic 12-core biopsies were taken for all patients using automatic disposable biopsy instrument and an 18-gauge (Monopty ${ }^{\circledR}$, BARD $^{\circledR}$, Tempe, USA). Additional 1-2 biopsies were obtained from any suspicious area in the prostate (hard nodule by DRE or hypoechoic lesion on TRUS).

\subsection{Outcome evaluation}

Primary outcome was incidence of post-TRUS-PB sepsis necessitating hospital admission. Sepsis was documented in the presence of two or more of fever $\geq 38^{\circ} \mathrm{C}$, leukocytosis $\left(<12,000 / \mathrm{mm}^{3}\right)$ and tachycardia $<90 / \mathrm{min}$. Septic shock included the previous in addition to hypotension. Post-biopsy complications were graded according to modified Clavien classification [12].

\subsection{Statistical analysis}

Statistical analysis was performed using SPSS v20 Program. Categorical data were expressed as numbers and percentages and then compared between groups using Chi-square test or Fisher's exact test. Continuous data were expressed as mean and standard deviations (SD) or median and interquartile range (IQR) if the values were not normally distributed and then compared using $t$ test or Mann-Whitney $\mathrm{U}$ test. $P$ value $<0.05$ was considered significant.

\section{Results}

The study included 146 patients (group 1 included 54 patients and group 2 included 92 patients). Mean age was 64 years (SD 8.7). Median PSA level was $8.9 \mathrm{ng} / \mathrm{ml}$ (IQR 6-15.6). The baseline characters were comparable for both groups (Table 1). Prostate cancer was detected in 56 patients (38.5\%).

The overall incidence of post-TRUS-PB sepsis was $2.7 \%$ (4 out of 146 patients). It was observed in three patients in group $1(5.6 \%)$ and one patient in group $2(1.1 \%)$, but the difference was insignificant $(P=0.143)$. Sepsis developed within $48 \mathrm{~h}$ after TRUS-PB, and E. coli was detected from blood culture in the four patients. Antibiotic sensitivity showed resistance to ciprofloxacin in two patients. Sepsis was successfully managed with IV antibiotics, fluids and antipyretics for three patients (Grade 2 complication), while one patient (1.9\%) from group 1 required ICU admission for management of septic shock (Grade 4a complications). Post-biopsy urinary retention developed in one patient from group 2 and was catheterized for 5 days (Grade 3a complication). 
Table 1 Pre-TRUS-guided prostatic biopsy patients' data

\begin{tabular}{|c|c|c|c|}
\hline Character & $\begin{array}{l}\text { Group } 1 \\
54 \text { Patients }\end{array}$ & $\begin{array}{l}\text { Group } 2 \\
92 \text { Patients }\end{array}$ & $P$ value \\
\hline Age in years: mean (SD) & $65.8(10.4)$ & $63.1(7.4)$ & $0.070^{*}$ \\
\hline PSA (ng/ml): median (IQR) & $10(7.3-17.7)$ & $8.5(6-14.9)$ & $0.382^{\&}$ \\
\hline Prostate size (CC): Median (IQR) & $45(30-69)$ & $45(29.6-60)$ & $0.508^{\&}$ \\
\hline Character & $N(\%)$ & $N(\%)$ & $P$ value \\
\hline Diabetes & $21(39)$ & $37(40)$ & 0.847 \\
\hline Hypertension & $28(52)$ & $42(45.7)$ & 0.469 \\
\hline Cardiac Ischemia & $10(18.5)$ & $16(17.4)$ & 0.864 \\
\hline ASA Score & & & 0.059 \\
\hline I & $17(31.5)$ & $37(40.2)$ & \\
\hline$\|$ & $31(57.4)$ & $53(57.6)$ & \\
\hline III & $6(11.1)$ & $2(2.2)$ & \\
\hline Urethral catheter & & & 0.372 \\
\hline No & $44(81.5)$ & $80(87)$ & \\
\hline Yes & $10(11.5)$ & 12 (13) & \\
\hline
\end{tabular}

Some patients had more than one comorbidity

$I Q R$ inter-quartile range

${ }^{*} t$ test, ${ }^{\&}$ Mann-Whitney $U$ test, ${ }^{~} C h i$ square test

\section{Discussion}

Sepsis and septic shock are major complications of TRUS-PB because they require hospital admission, urgent treatment and sometimes ICU admission. The incidence of post-TRUS-PB sepsis ranged from 0.17 to $5.7 \%$ [13-15]. The overall incidence of sepsis in the present study $(2.7 \%)$ was within the published range of previous reports [13-15]. More sepsis (5.6\%) was observed in group 1 (patients who started ciprofloxacin after prostatic biopsies) in comparison with group 2 (1.1\%) (those who started ciprofloxacin 1 day before the biopsies). This difference was not statistically significant but starting oral antibiotic after the biopsies was associated with 1.9\% incidence of septic shock, which is more than previously reported range of $0.2-0.45 \%[13,14]$. On the other hand, antibiotic administration prior to biopsies was not associated with septic shock in all patients in group 2.

There is no single accepted protocol for antibiotic prophylaxis for TRUS-PB with regard to antibiotic class, number, timing of start and duration [8]. In most of the recent protocols, two antibiotics were used (a fluoroquinolone and an aminoglycoside) [15-17] or a specific antibiotic based on rectal swab culture and sensitivity results $[7,15,18]$. The emerging need for this was the escalating incidence of fluoroquinolone resistant bacteria in rectal flora to reach $22 \%$ in one study [19] and up to $83 \%$ in another report [15]. A combination of ciprofloxacin and amikacin was used in the current study to combat fluoroquinolone resistant bacteria. It was reported by Kehinde et al. [17] that adding amikacin to ciprofloxacin significantly decreased the rate of TRUS-PB sepsis. Yang et al. [16], in their recent meta-analysis, concluded that adding one antibiotic to the basic agent may contribute to minimizing infection severity. This was proved in the present study as no patient in group 2 developed septic shock. Elshal et al. [15] had found that two antibiotics administration was associated with lesser incidence of post-TRUSPB infectious complications than rectal swab-based prophylaxis. Steensels et al. [19] had found that the use of fluoroquinolones in the previous 6 months before TRUS-PB was a risk factor for fluoroquinolone-resistant E. coli. Therefore, patients who received fluoroquinolones within 6 months prior to TRUS-PB can benefit from rectal swab-based prophylaxis.

In the first three consecutive years of the present study, ciprofloxacin was started immediately after TRUS-PB based on two previous studies that showed no differences in infectious complications between those who started antibiotic before or immediately after TRUSPB $[9,10]$. In the last month of this period, two cases of post-biopsy sepsis were encountered and one of them developed septic shock. This created the need to reconsider the antibiotic prophylaxis regimen adopted. Since then we started ciprofloxacin 1 day before TRUS-PB. This protocol resulted in reducing the incidence of sepsis and avoidance of septic shock. Manecksha et al. [11] also reported that starting antibiotic $24 \mathrm{~h}$ before TRUS-PB 
Table 2 Antibiotic prophylaxis protocols and incidence of sepsis after TRUS-PB in contemporary reports

\begin{tabular}{|c|c|c|c|}
\hline Reference & No. of patients & Antibiotic policy & Sepsis \% \\
\hline Rumaihi et al. [20] & 455 & $\begin{array}{l}\text { G 1: Ciprofloxacin } 500 \mathrm{mg} 2 \text { days before the procedure and } 3 \text { days after } \\
\text { G 2:The same + Cefuroxime } 1.5 \mathrm{~g} \text { IV } 30 \text { min before the procedure }\end{array}$ & $\begin{array}{l}\text { G } 1: 8.8 \% \\
\text { G } 2: 3.6 \%\end{array}$ \\
\hline Manecksha et al. [11] & 1183 & $\begin{array}{l}\text { G 1: Ofloxacin } 400 \mathrm{mg} \text { immediately before the procedure and } 200 \mathrm{mg} \text { twice daily } 3 \text { days after } \\
\text { G2: Ofloxacin } 200 \mathrm{mg} \text { twice daily for } 3 \text { days commencing } 24 \mathrm{~h} \text { before the procedure }\end{array}$ & $\begin{array}{l}\text { G } 1: 3.6 \% \\
\text { G2: } 1.6 \%\end{array}$ \\
\hline Kehinde et al. [17] & 1197 & $\begin{array}{l}\text { G 1: Ciprofloxacin } 500 \mathrm{mg} \text { twice daily } 1 \text { day the procedure and } 2 \text { days after } \\
\text { G 2: the same + IV Amikacin } 500 \mathrm{mg} 30 \text { min before the procedure }\end{array}$ & $\begin{array}{l}\text { G } 1: 8 \% \\
\text { G } 2: 1.7 \%\end{array}$ \\
\hline Rudziniski et al. [14] & 927 & 3-day course of oral antibiotic prior to the biopsy & $2.2 \%$ \\
\hline Singh et al. [7] & 247 & $\begin{array}{l}\text { According to rectal swab } \\
\text { Fluoroquinolone sensitive; } \\
\text { Oral Ciprofloxacin } 500 \text { mg + Tinidazole } 600 \text { mg } \\
\text { Fluoroquinolone resistant; } \\
\text { Culture directed antibiotics }\end{array}$ & $0 \%$ \\
\hline El Shal et al. [15] & 469 & $\begin{array}{l}\text { Standard prophylaxis } \\
\text { Ciprofloxacin } 500 \text { mg BD } 3 \text { days starting the night of the biopsy } \\
\text { Augmented Prophylaxis } \\
\text { Ciprofloxacin + Single dose of gentamicin } 160 \mathrm{mg} \text { IM at the biopsy } \\
\text { Targeted prophylaxis } \\
\text { According to rectal swab culture }\end{array}$ & $\begin{array}{l}2 \% \\
0.6 \% \\
4.3 \%\end{array}$ \\
\hline Present study 2018 & 146 & $\begin{array}{l}\text { G 1: } 1 \mathrm{~g} \text { Amikacin } 30 \text { min before the biopsy and ciprofloxacin } 500 \text { mg oral immediately after } \\
\text { the procedure for } 5 \text { days } \\
\text { G 2: The same as Group } 1+\text { Ciprofloxacin started } 1 \text { day before the biopsy }\end{array}$ & $\begin{array}{l}\mathrm{G} 1: 5.6 \% \\
\mathrm{G} 2: 1.1 \%\end{array}$ \\
\hline
\end{tabular}

G 1 Group 1, G 2 Group 2

was associated with $55 \%$ reduction in the relative risk of infectious complications.

Duration of antibiotic prophylaxis was also a controversial issue as some authors used single dose of antibiotic $[9,10]$, others used it for 3 days $[11,17]$ or 5 days [20]. In a meta-analysis of 22 randomized controlled trials, Yang et al. had found twofold of greater risk of bacteriuria for short-course treatment and single-dose treatment when compared with long-course. They also concluded that using two antibiotics for long-course can decrease development of drug resistance [16]. In the present study, we administered ciprofloxacin for 5 days to achieve the value of lesser post-biopsy infections and minimize the chances of drug resistance.

The antibiotic prophylaxis protocols and incidence of sepsis after TRUS-PB in contemporary reports are summarized in Table 2. The highest incidence of postTRUS-PB sepsis was observed in patients who received ciprofloxacin alone $[17,20]$, while the lowest incidence was reported with antibiotic prophylaxis depending on rectal swab cultures [7].

One of the limitations of this study is retrospective design that affected our ability to report minor complications such as rectal bleeding, mild hematuria and hemospermia because the data about these complications were incomplete. Another limitation is the relatively small sample size in group 1 . Therefore, multivariate analysis for risk factors was not performed.

\section{Conclusions}

The incidence of sepsis after TRUS-PB is low when dual antibiotic prophylaxis (ciprofloxacin and amikacin) was used. Starting oral ciprofloxacin 1 day prior to TRUS-PB decreased the incidence of sepsis as well as its severity.

\section{Abbreviations}

TRUS: transrectal ultrasound; TRUS-PB: transrectal ultrasound-guided prostatic biopsies; ASA: American Society of Anesthesia; PSA: prostatic specific antigen; EAU: European Association of Urology; DRE: digital rectal examination; INR: international normalization ratio; UTI: urinary tract infection; SD: standard deviations; IQR: interquartile range.

\section{Acknowledgements \\ Not applicable.}

\section{Authors' contributions}

MF was involved in data acquisition, SMS revised the manuscript, ARE was involved in conception, data analysis and drafting the manuscript, TFA revised the manuscript, and AA designed the work. All authors have read and approved the final manuscript.

\section{Funding \\ No funding.}

\section{Availability of data and materials}

Data are available on request.

Ethics approval and consent to participate: (IRB number: 2018-18)

All procedures performed in this study were in accordance with the ethical standards of the institutional research committee and with the 1964 Helsinki Declaration and its later amendments or comparable ethical standards.

Consent for publication

No applicable. 


\section{Competing interests}

The authors declare that they have no conflict of interest.

Received: 7 January 2020 Accepted: 28 January 2020

Published online: 04 May 2020

\section{References}

1. Jemal A, Lortet-tieulent J, Ward E, Ferlay J, Brawley O, Bray F (2012) International variation in prostate cancer incidence and mortality rates. Eur Urol 61:1079-1092. https://doi.org/10.1016/j.eururo.2012.02.054

2. Loeb S, Carter HB, Berndt SI, Ricker W, Schaeffer EM (2011) Complications after prostate biopsy: data from SEER-medicare. J Urol 186:1830-1834. https://doi.org/10.1016/j.juro.2011.06.057

3. Ecke TH, Gunia S, Bartel P, Hallmann S, Koch S, Ruttloff J (2008) Complications and risk factors of transrectal ultrasound guided needle biopsies of the prostate evaluated by questionnaire. Urol Oncol 26:474-478. https:// doi.org/10.1016/j.urolonc.2007.12.003

4. Pinkhasov Gl, Lin YK, Palmerola R, Smith P, Mahon F, Kaag MG et al (2012) Complications following prostate needle biopsy requiring hospital admission or emergency department visits-experience from 1000 consecutive cases. BJU Int 110:369-374. https://doi.org/10.1111/j.1464410X.2011.10926.x

5. Nam RK, Saskin R, Lee Y, Liu Y, Law C, Klotz LH et al (2013) Increasing hospital admission rates for urological complications after transrectal ultrasound guided prostate biopsy. JURO 189:S12-S18. https://doi. org/10.1016/j.juro.2012.11.015

6. Mottet N, Bellmunt J, Bolla M, Briers E, Cumberbatch MG, De Santis $M$ et al (2017) EAU-ESTRO-SIOG guidelines on prostate cancer. Part 1: screening, diagnosis, and local treatment with curative intent. Eur Urol 71:618-629. https://doi.org/10.1016/j.eururo.2016.08.003

7. Singh P, Kumar A, Yadav S, Prakash L, Nayak B, Kumar R et al (2017) "Targeted" prophylaxis: impact of rectal swab culture-directed prophylaxis on infectious complications after transrectal ultrasound-guided prostate biopsy. Investig Clin Urol 58:365-370

8. Hillelsohn JH, Duty B, Blute ML, Okhunov Z, Kashan M, Moldwin R et al (2012) Variability of transrectal ultrasound-guided prostate biopsy prophylactic measures. Can J Urol 19:6573-6577

9. Argyropoulos AN, Doumas K, Farmakis A, Liakatas I, Gkialas I, Lykourinas M (2007) Time of administration of a single dose of oral levofloxacin and its effect in infectious complications from transrectal prostate biopsy. Int Urol Nephrol 39:897-903. https://doi.org/10.1007/s11255-006-9112-7

10. Lindstedt S, Lindstrom U, Ljunggren E, Wullt B, Grabe M (2006) Singledose antibiotic prophylaxis in core prostate biopsy: impact of timing and identification of risk factors. Eur Urol 50:832-837. https://doi. org/10.1016/j.eururo.2006.05.003
11. Manecksha RP, Nason GJ, Cullen IM, Fennell P, Mcevoy E, Mcdermott T et al (2012) Prospective study of antibiotic prophylaxis for prostate biopsy involving > 1100 men. Sci J 2012:650858. https://doi. org/10.1100/2012/650858

12. Dindo D, Demartines N, Clavien P (2004) Classif Surg Complicat 240:205213. https://doi.org/10.1097/01.sla.0000133083.54934.ae

13. Klemann N, Helgstrand JT, Brasso K, Vainer B, Iversen P et al (2017) Antibiotic prophylaxis and complications following prostate biopsies-a systematic review. Dan Med J 64:A5323

14. Rudzinski JK, Kawakami J (2014) Incidence of infectious complications following transrectal ultrasound-guided prostate biopsy in Calgary, Alberta, Canada: a retrospective population-based analysis. J Can Urol Assoc 8:301-305. https://doi.org/10.5489/cuaj.1751

15. Elshal AM, Atwa AM, El-Nahas AR, El-Ghar MA, Gaber A, Elsawy E et al (2018) Chemoprophylaxis during transrectal prostate needle biopsy: critical analysis through randomized clinical trial. World J Urol. https://doi. org/10.1007/s00345-018-2319-2

16. Yang L, Gao L, Chen Y, Tang Z, Liu L, Han P et al (2015) Prophylactic antibiotics in prostate biopsy: a meta-analysis based on randomized controlled trials. Surg Infect 16:733-747. https://doi.org/10.1089/sur.2015.040

17. Kehinde EO, Al-maghrebi M, Sheikh M, Anim JT (2013) Combined ciprofloxacin and amikacin prophylaxis in the prevention of septicemia after transrectal ultrasound guided biopsy of the prostate. JURO 189:911-915. https://doi.org/10.1016/j.juro.2012.08.237

18. Scott S, Harris PN, Williamson DA, Liss MA, Doi SAR, Roberts MJ (2018) The effectiveness of targeted relative to empiric prophylaxis on infectious complications after transrectal ultrasound-guided prostate biopsy: a meta-analysis. World J Urol 36:1007-1017. https://doi.org/10.1007/s0034 5-018-2217-7

19. Steensels D, Slabbaert K, De Wever L, Vermeersch P, Van Poppel H, Verhaegen J (2011) Fluoroquinolone-resistant E. coli in intestinal flora of patients undergoing transrectal ultrasound-guided prostate biopsy-should we reassess our practices for antibiotic prophylaxis? Clin Microbiol Infect 18:575-581. https://doi.org/10.1111/j.1469-0691.2011.03638.x

20. Al Rumaihi K, Majzoub AA, Younes N, Shokeir A (2012) Does intravenous cefuroxime improve the efficacy of ciprofloxacin for preventing infectious complications after transrectal prostate biopsy? A prospective comparative study. Arab J Urol 10:388-393. https://doi.org/10.1016/j. aju.2012.04.004

\section{Publisher's Note}

Springer Nature remains neutral with regard to jurisdictional claims in published maps and institutional affiliations.

\section{Submit your manuscript to a SpringerOpen ${ }^{\circ}$ journal and benefit from:}

- Convenient online submission

- Rigorous peer review

- Open access: articles freely available online

- High visibility within the field

- Retaining the copyright to your article

Submit your next manuscript at $\mathbf{\Delta}$ springeropen.com 